01

\title{
TRANSDISCIPLINARITY REVISITED: TRANSFORMATIVE POTENTIAL OF LESSONS WE MIGHT LEARN
}

\author{
Christoph Woiwode and Olivia Bina
}

\section{Introduction}

The title, "Enabling the City - inter- and transdisciplinary encounters and challenges in research and practice" emphasises the enabling environment and conditions that facilitate inter- and transdisciplinary processes. In order to enrich this discussion, it is helpful to explore the relationship between multi-, inter- and transdisciplinarity from additional perspectives compared with those introduced in Part I, offering alternative interpretative layers to the definitions offered in Chapter I.3. In particular, we wish to explore both a critique of these approaches to knowledge production, and the possibility of a transformative potential, also discussed in Chapter IV.3.

\section{Does Transdisciplinarity “Change Everything”?}

As noted by the editors, the literature on inter- and more recently transdisciplinarity has increased rapidly in the past 10 to 15 years. With the latter term going back to the early 1970 s when focusing on a more philosophical notion of synthesising and unifying disciplinary knowledge with research, science and technology within and for higher education institutions, "the notion of transdisciplinarity introduced at the beginning of the 1970s remained undeveloped and almost uncited until the early 1990s" (Bernstein, 2015, p.3).

With respect to the planning professions and urban development planning, we do acknowledge that these are widely considered interdisciplinary fields of practice that take into account such diverse fields as economic, legal, historical, social, ecological, design, technical, engineering and political dimensions, among others. It is at least a field of multidisciplinary engagement and interaction. Multidisciplinarity brings together the work of multiple disciplines operating in a relatively self-

FIGURE IV.1.1 Exposure visit at Lokhalle Freiburg during the Second Indo-German Dialogue on Green Urban Practices about "Education, learning, training and awareness for sustainable development," in Freiburg, November 2018. Photo by C. Woiwode. 
contained and independent manner with the integration across disciplines being limited to the summation of findings (Riedy, 2007). Its aim is mainly the juxtaposition of theoretical models belonging to different disciplines. Disciplines are considered as being complementary in the process of understanding phenomena. The point is not to take into account the entire model, but only part of each model; which can be the object of bilateral consensus, in order to maintain coherence. The advantage of this approach is that it highlights the different dimensions of the studied object and respects the plurality of points of view (Ramadier, 2004).

In contrast, interdisciplinary research goes further, seeking to integrate disciplinary perspectives on a particular problem to provide a systemic outcome - for example, through a strategic spatial urban development plan - but disciplinary boundaries are not transgressed (Riedy, 2007). Interdisciplinarity differs from multidisciplinarity in that it constructs a common model for the disciplines involved, based on a process of dialogue between disciplines. For this reason, interdisciplinarity is often implemented within the same disciplinary field and its purpose is to create synthesis. However, the second important aspect of interdisciplinarity lies in the practice of transfers, either of models or of tools (such as mathematics or statistics), from one discipline to others. In terms of its limitations, interdisciplinarity, like multidisciplinarity, avoids paradoxes and having to solve them. As a result, both interdisciplinarity and multidisciplinarity approaches are fragmented. As Ramadier (2004, p.433) argues, multidisciplinarity and interdisciplinarity do not break with disciplinary thinking.

Disciplinarity remains, indeed, a pillar of how knowledge is produced, even when projects are designed with an inter- and transdisciplinary approach. Partly, as also confirmed in many gatherings promoted by INTREPID (see Chapter I. 2 in this volume), there remains a core belief that to go beyond disciplines you first need to have a solid basis in one of them. The definitions and interpretations of transdisciplinary work may help here, but they do vary significantly depending on the worldview that underpins them. It is within this arena that we believe a key can be found towards greater transformation and therefore propose to explore transdisciplinarity in greater detail by drawing on the work of Basarab Nicolescu (2002), President of the International Centre for Transdisciplinary Research, who offers one of the most comprehensive views on transdisciplinarity; one that is transcultural, transhistorical, transpolitical. It seeks to integrate (and acknowledge) knowledge diachronically throughout history and synchronically from "East" and "West," perennial philosophies and the sciences (Woiwode, 2013). By conceiving of knowledge being produced between, across and beyond disciplines, Nicolescu (2002) reveals the transformative potential of transdisciplinarity.

\section{Three Perspectives}

According to Nicolescu, the term "transdisciplinarity" can assume and be used in three different ways. Firstly, as a philosophy (a stance, placing it in the larger context of our existence); secondly, an epistemology (relating to the integration and unity of knowledge, i.e. non-dualism); and thirdly, a methodology (resolving practical issues in problem-oriented scientific research, particularly environmental studies) (Woiwode, 2013, p.386).

The philosophical and epistemic dimensions are closely linked. He elaborates further on the transgressive character of the concept: "As the prefix trans indicates, transdisciplinarity concerns that which is at once between the disciplines, across the different disciplines, and beyond all discipline. Its goal is the understanding of the present world, of which one of the imperatives is the unity of knowledge" (Nicolescu, 2002, p.44). From this point of view, transdisciplinarity would essentially 
transgress the duality of opposing binary pairs such as subject/object, subjectivity/objectivity, matter/consciousness, nature/divine, simplicity/complexity, reductionism/holism, diversity/unity (Nicolescu, 2002). As a result, transdisciplinarity seeks to break down and overcome - i.e. transgress - traditional disciplinary boundaries and organise "knowledge around complex heterogeneous domains" (Riedy, 2007, p.26). In moving beyond disciplines, transdisciplinary research attempts to generate synergies and provides opportunities to generate new types of knowledge with the goal of recreating integrated knowledge (Sommerville and Rapport, 2000). As an approach to research and practice, it is a particularly suitable response to complex wicked problems such as climate change that cannot be treated by the application of fragmented disciplinary knowledge (Hoffmann-Riem et al., 2008 ) but need to be seen from a systems perspective. In our view, this aspect permits a bridge to other bodies of literature concerned with (w)holism but which is normally not linked to debates of transdisciplinarity (e.g. Capra and Luisi, 2014).

Moving on to Nicolescu's third point, we find transdisciplinarity as a methodology: a focused but relatively narrow notion that happens to be the one mostly referred to and applied by academics and practitioners. A high-profile example of such a focused view of transdisciplinarity can be found in the influential Flagship Report by the German Advisory Council on Global Change (WBGU, 2011), which explores transformative and transformational research towards sustainable societies in detail. It appears that in this publication it is mostly viewed and discussed as a methodology, placing less focus (or awareness) on the underpinning philosophical dimensions outlined earlier and how they may affect multi-agent, multi-stakeholder and pluralistic knowledge arenas. Its authors focus mainly on the aspect of including and involving social actors and stakeholders in identifying the research questions and conducting research: "Transdisciplinarity encompasses a range of different aspects. Firstly, it means increasing the social relevance of research questions through the involvement of stakeholders in setting research goals. Secondly, it also applies to the involvement of stakeholders in the actual research process, i.e., the combination of scientific and practical knowledge (for example local, traditional or indigenous knowledge)" (WBGU, 2011, p.323). With this twofold notion of transdisciplinarity, the link to social transformation is established. According to the WBGU's approach, for transdisciplinarity to be relevant in terms of inducing social transformation, the research needs to become part of and be linked to society - it must be socially relevant - and simultaneously incorporate, acknowledge and honour local and indigenous ways of knowing.

In practical terms, this somewhat lengthy elaboration on transdisciplinarity is useful, with reference to how knowledge is being created in terms of power relationships of knowledge co-production, and the role of Western science as a predominant way of knowing, as Amartya Sen (2000) pointed out aptly in his analysis on the social acceptance of types of knowledge in specific social-cultural contexts. Beyond this, the transdisciplinary paradigm also poses a critique of the colonial legacies and therefore challenges the current postcolonial condition and knowledge imperialism that has long dominated the relationship of the Western world with the rest of the world. From this viewpoint, transdisciplinarity includes critical issues of empowerment, particularly with respect to equality of diverse modes of knowing, hence going far beyond just addressing to resolve complex (environmental) issues of the world. Therefore, "TD [transdisciplinarity] became aligned with imperatives of cultural critique, socio-political movements, and conceptions of post-normal science and wicked problems that break free of reductionist and mechanistic approaches" (Klein, 2015, p.10). 


\section{Transformative Potential: Additional Perspectives}

Having argued that transdisciplinary knowledge holds the promise of disciplinary transgression and - through the process of knowledge creation itself - of social transformation, it is useful to link to existing theories and perspectives that have increasingly informed debates on knowledge for (sustainable) transition and transformation. These tend to depart from the idea of a "social milieu" as a concept that describes an existing environment in somewhat passive terms, and instead explore the emergence of social innovations or "alternative milieus" where inter- and transdisciplinarity may emerge and facilitate change, turning the social milieu into a "fertile ground." A key area of research and theory is that of sustainability transitions (Murphy, 2015; Loorbach et al., 2017), which seeks to understand the emergence of social innovations or "alternative milieus," in particular socio-spatial configurations and the promotion of these by way of "protective niches" (Longhurst, 2015). Many of the case studies and practice stories in Parts II and III of this volume take this proactive perspective, and through a combination of inter- and transdisciplinarity, seek to open alternative spaces of thinking and knowing the city and the urban projects at their different scales. The framework's four phases of an inter- and transdisciplinary process, combined with its four process enablers introduced in Part I (Chapter I.2) can be viewed as framing the phases and qualities that allow for the emergence of alternative milieus.

This link to transition theory and research calls for another connection. The premise of transdisciplinarity is, of course, also closely related to action research and planning. Reason and Bradbury (2001), for instance, point out the participatory dimension of action research in co-creating knowledge mutually between the researchers and the people to generate "practical knowing" through action and reflection, theory and practice. Action research as a worldview thus encompasses a significant element to change or transform existing social realities. Indeed, it is rooted in the same recognition of an emergent worldview which "has been described as systemic, holistic, relational, feminine, experiential [...]" (Reason and Bradbury, 2001, p.6). A core dimension of an action-oriented approach to transdisciplinarity asks the question: who are the active change agents, the stakeholders involved? From such an action-oriented perspective, transdisciplinarity suggests that we are broadly talking about academic and non-academic actors. In Parts I and II (of this volume), transdisciplinarity is conceived as quintessentially collaborative, including co-creative, given the emphasis on co-design and co-production, but also on dissemination and outreach, as well as continuation (i.e. the four phases of the Framework developed in Chapter I.2); all of which require high levels of collaboration and related competences and dispositions.

This in turn allows a link to those action-oriented approaches such as living and real-world labs and transformative change (Engels and Walz, 2018; Schäpke et al., 2018), the subject of the Stuttgart case study (Chapter II.5, this volume) where the German government funded a project that "showcases the enabling conditions for the production of joint knowledge through experimental design projects related to the urban environment" highlighting the special role played by "change agents" who are spearheading and pioneering new, innovative solutions. Considered a relevant methodology in transdisciplinary projects, the concept and format of real-world labs (RWLs) has recently thrived in urbanrelated research and practice, mainly thanks to the inclusion of experimentation and prototyping, testing as practised in urban living labs (see Puerari et al., 2018). The term "real-world lab" is a catch-all phrase for a diverse set of methods, as outlined by Schäpke et al. (2018, p.85): "New forms of real-world experimentation, such as (sustainability) living labs (SLLs) (e.g., Liedtke et al. 2015), urban transition labs (UTLs) (e.g., Nevens et al. 2013), transformation labs (T-Labs) (e.g., Olsson 2016), and real-world laboratories (RwLs) (e.g., Wagner and Grunwald 2015), attempt to merge the strengths of laboratory settings with the advantages of conducting research in the real world (Caniglia et al. 2017)." 
Another area of particular relevance in the context of urban development opened up by transdisciplinarity is public engagement. Innovative interactions to create tangible outputs in critical areas such as urban climate change adaption and mitigation between science/academia and the public through the arts, especially performing arts such as dance, theatre, film or embodiment art, or even literature, are part of a relatively new academic field of the environmental humanities (e.g. Bergthaller et al., 2014; Dieleman, 2015). One such intricate case exemplifying an integrative approach across the arts and humanities combining participatory action research to collaboratively produce outputs relating to urban water is the Hydrocitizenship project, which was carried out across several cities in the UK (https://www.hydrocitizenship.com). ${ }^{1}$ These disciplinary interfaces are becoming more popular and recognised, but overall remain largely uncharted territory in most urban development processes, as shown also by their minor role within the scope of this book.

Thus, the transformative potential of transdisciplinarity, and thus of the authors' proposed Framework, can be understood from the perspectives of Nicolescu, but also through the links with sustainability transition research, action-oriented research, the broad notion of public engagement, and finally through the lens of environmental humanities and their integration of the arts.

\section{Enabling Conditions and Their Potential}

Parts II and III of this book contain 16 stories and empirical evidence of inter- and transdisciplinary research and practice, providing a fascinating set of on-the-ground experiences that explore the diverse and highly creative, experimental character of transdisciplinary project designs and ways of implementation. A good illustration of this, which will catch the eye of any social anthropologist, can be found in Chapter II.1, "The Place and Space of Power: Mess, Uncertainty and Change over Time."

This tells the story of how ethnographers may be key contributors to the success of a project: "the experience of an ethnographer embedded in the project and how this encouraged and enabled team members to be reflexive about the transdisciplinary research process throughout the life of the project, and kept interdisciplinarity at the core of reflection. Understanding and approaching interdisciplinarity in this way has foregrounded the importance of the experiential knowledge of and 'spillover' effects such working creates."

Taken together, a number of noteworthy thematic areas that support an enabling environment emerge from the various case studies and practice stories presented in this volume. They echo the main phases and enabling conditions of the framework proposed in Part I, but they also connect to ideas of social transformation and to inter- and transdisciplinary urban research as a means to serve emergent alternative worldviews and solutions. By combining these different insights, we seek to extract five lessons to be learnt by the wider community of civil society, including researchers and practitioners, involved in the complex processes of urbanisation.

Firstly, having sought to highlight the transformative potential of inter- and transdisciplinary processes, we start with a reflection on the term transformation, also as a confirmation that "words" indeed "matter," as emphasised by Mennes (Chapter I.3), and will suggest that there are three sides to this: transformation of the built environment, of relationships and of the self. Transformation or transformational are at the centre of the notion of (urban) development and they mostly refer to the built environment (see Parts II and III: the swimming pool, the main street, mobility, housing/ building, the whole place); however, it has been made abundantly clear in this volume that as much transformation, if not more, is entailed in terms of the relationships between the multiple actors involved, and that such change is itself predicated on the disposition and capacity for self-reflection 
and learning. Hence, the emphasis on learning in the framework presented by Bina et al. in Chapter I.2, which links to the idea of "transformative learning," potentially introduces an entirely different, and yet related, theoretical body of literature on this topic dating as far back as the 1990s and early 2000s (e.g. Brookfield, 2000; Illeris, 2013; Mezirow, 1991; Taylor, 2007).

Secondly, there is a clear link between the issue of what is being transformed (or attempted), and the dimension of "Enabling the City" that sees the involvement of multiple actors and stakeholders, and the enabling collaborative processes of knowledge production, as key. WBGU's flagship report (2011) distinguishes between involving actors from outside academia to set research goals and involving them in the actual research process. This distinction, and its challenging implications, are captured in the four, closely overlapping, phases of the Framework developed in Chapter I.2: by noting the need of involvement in design, production, dissemination and continuation, the framework emphasises, among other things, the need for time and resources, as well as commitment. The 16 stories explored in Parts II and III show how difficult this is in practice, and how even successful outcomes may be potentially fragile, notably because of the rare commitment to "continuation."

Thirdly, if the immediate aim of the urban project may at times be frustrated (see for example, Chapter II.7 in this volume), nonetheless, the notion of "outcomes" is necessarily diverse, and here one of the emphases is precisely capturing the less tangible but perhaps critical dimension of longterm change. The potential for social relevance and social transformation is indeed highlighted in transition research, and viewed as a process that inter- and transdisciplinarity (especially from the perspective of Nicolescu, 2002) can contribute to. Regarding this, we have argued earlier that the processes of urban knowledge production need to incorporate, acknowledge and honour different ways of knowing (WBGU, 2011) throughout all four phases of the framework discussed here. To achieve this, the framework's four enabling conditions become essential: the need to develop the necessary competences and dispositions to conceive and manage the process of engagement and collaboration, the sensibility towards the contexts of the actors and stakeholders whose diverse ways of knowing need to matter, the attention towards words and thus language in all its diverse meanings, and finally the need for time to cover all this ground and to learn throughout the process. Social learning is an inherent dimension of knowledge co-production, self-reflection and collaboration with multiple and diverse actors and perspectives (but also needs/demands/expectations); it depends on the capacity to build trust and relationships, a capacity identified in most cases discussed in Part II and Part III, suggesting that this is a key element to the success of inter- and transdisciplinary projects.

Fourthly, the emphasis on four, closely overlapping, phases of inter- and transdisciplinary processes in the framework is also a way of highlighting precisely the uncertainty of urban processes that depend on the success and failures (courageously acknowledged in this volume) of collaboration. In essence, while these processes are conceived and designed precisely to address the rising levels of uncertainty in urban development, they may (or even will) also contribute to it. This evolving character of practice (we would call it "emergence"), which seems intrinsic to transdisciplinary processes (see also Chapter I.1 in this volume) challenges at its roots the modernist, twentieth-century, established, traditional, objectives-driven and instrumental urban planning and project management approaches. This leaves us with a single question at the core: how do planners, policymakers and other stakeholders who are seeking to achieve a definite degree of certainty to predict future developments in order to steer the direction of development deal with the open-ended nature of emergence in transdisciplinary processes? Parts II and III are an attempt to answer this, revealing inevitably complex, at times messy, but almost always enriching and partly transformative journeys. 
Fifthly, there may be a need to integrate the four enabling conditions of the framework proposed by INTREPID's community, with a stronger awareness of a defining aspect of Nicolescu's approach: the philosophical and epistemic drivers of the need for more and better inter- and transdisciplinary processes. Most of the urban-related themes discussed in Parts II and III are typically complex (at times wicked) and always in need of a systemic approach: this demands transgression of disciplinary knowledge and heterogeneity in ways of knowing, as well as awareness of one's own biases and beliefs. Instead, a significant amount of resources and time must be dedicated to dissolve persistent dualities and narrow disciplinary framings. The enabling condition of "competences and dispositions" may hold the key to a greater awareness of this need for awareness and transgression; however, this will require far-reaching changes in mainstream higher education institutions.

On a final note, this volume, with its rich examples of practice, vividly illustrates the often critical ambiguity of the processes of transdisciplinarity in terms of its benefits and shortcomings. Thus, Andersen and Kirkeby (in Chapter II.8 of this volume) recognise the fine line that exists between barriers and potentials that may arise from diverse and plural perspectives. They point out that on the one hand, people often would not comprehend each other due to their varying social and other conditioning, the framing of cognitive mindsets; whereas, on the other hand, it is exactly due to these varying perspectives and plurality that there is an inherent opportunity in transdisciplinary processes to generate new knowledge. Consequently, as two inherently interdependent sides of the same coin, barriers and potentials must be addressed and seized in transdisciplinary projects in order to lead them to success.

\section{Concluding Remarks}

The three-dimensional Framework developed by the authors seeks to support researchers and practitioners in their planning and implementation of invariably complex and often unpredictable interand transdisciplinary journeys. As the need for interdisciplinarity and transdisciplinarity continues to expand, both in academic and practice circles, not least thanks to the UN Agenda for Sustainable Development Goals (SDGs) and the New Urban Agenda (NUA) discussed in the introduction and in the final Chapter of this book we offer some concluding observations that depart from this volume and will require further discussion and consideration.

Firstly, the geographical scope: clearly, this volume focuses on Europe, but we may ask how and to what extent this approach and the related underpinning debates are applicable in non-European contexts? A challenge is how to drive and achieve global transitions towards sustainability. Cultural, political and civil society contexts are extremely diverse, posing tremendous challenges for all stakeholders involved, especially placing the issues of multiple and diverse ways of knowing centre stage (Nikulina et al., 2019). Can these frameworks fit in other contexts - say, the Brazilian or Indian or Indonesian? A significant contribution towards answering some of these questions is offered by the work of the Mistra Urban Futures network ${ }^{2}$, which carried out comparative work between European and African cities on transdisciplinary co-production practices, revealing many points of common learning (Patel et al., 2017; Perry et al., 2018; Simon, 2016). No doubt this approach to urban research and practice poses a formidable task, similar to breaking down the NUA or SDGs in a meaningful and contextually sensitive manner: a cross-cultural engagement of this sort needs regional and local expertise.

Secondly, whose voice is being heard? In compiling this volume, the editors made a conscious effort to explore experience of inter- and transdisciplinary processes through the lens of academia and practice. Thus, case studies in Part II and practice stories in Part III seek to give voice to diverse 
expertise, yet the experience showed clear limitations regarding the current ethos of much academic publishing: firstly, the language and "scientific" style of writing remains a constraint for those outside academia (a typical obstacle is the need to cross-reference to existing academic literature). Secondly, the very different writing styles, even within "scientific writing," arising from disciplinary traditions, mean that an edited book that is both inter- and transdisciplinary becomes a double challenge (Durose et al., 2018). The understandable expectation that a volume presents a coherent style leads to difficult impositions, and the need to sacrifice distinct style and visual language. Thirdly, academic publications, even when they attempt to accommodate some of the differences, as this volume has sought to do, entail time and resources that non-academic agents will often find difficult to justify and prioritise. The issue of resources and time links back to the Framework's (Chapter I.2) emphasis on the four phases of inter- and transdisciplinary processes and the need to plan, and fund, co-design and co-production as well as a continuation phase, which is almost never considered.

Thirdly, ethical implications: inevitably, as research opens to the co-design and co-production of knowledge to a complex and diverse context of multiple agents, it becomes more challenging to ascertain what the ethical issues of collaborative work are (such as confidentiality, consent, anonymity, data protection and usage, publication, ownership, etc.). The "importance of setting a clear ethical framework in developing a methodological approach" for inter- and transdisciplinary projects, as noted by Dimitrova (Chapter II.7 in this volume) becomes pressing, and is partly linked to our earlier point regarding time, commitment and funding for participating and publishing.

We have sought to explore further the transformative potential of inter- and transdisciplinary practices of knowing, and of learning, as emphasised in the structure of the Framework developed by the authors. These practices are certainly fundamental to help create the knowledge that can shape more socially and ecologically sustainable futures, but they remain open to practical and epistemological obstacles, which require, at the very least, significant additional effort from all involved. For now, the transformative potential is clearly identifiable in the experience of these processes and the learning that comes with them.

\section{Notes}

1 The Hydrocitizenship project ran from 2014 to 2017. It was an AHRC-funded project which investigated and contributed to ways in which communities live with each other and their environment in relation to water in a range of UK neighbourhoods. The project is now finished. This website and the other linked sites provide a record of the activities and outputs from the project.

2 Mistra Urban Futures was formed in 2010 as a programme and centre for knowledge and research on sustainable urban development, funded by Mistra, Sida and a Gothenburg Consortium. The Centre brought together academics, professionals and other stakeholders for ten years to co-produce new knowledge and contributions towards urban transitions to more sustainable paths for development. As of January 2020, the Gothenburg part of the Centre has become Urban Futures. https://www.mistraurbanfutures.org/en

\section{References}

Bergthaller, H., Emmett, R., Johns-Putra, A., Kneitz, A., Lidstršm, S., McCorristine, S., Perez Ramos, I., Phillips, D., Rigby, K., \& Robin, L. (2014). Mapping common ground: Ecocriticism, environmental history, and the environmental humanities. Environmental Humanities, 5, 261-276.

Bernstein, J.H. (2015). Transdisciplinarity: A review of its origins, development, and current issues. Journal of Research Practice, 11(1), Article R1. Retrieved from http://jrp.icaap.org/index.php/jrp/article/view/510/412

Brookfield, S.D. (2000). Transformative learning as ideology critique. In: J. Mezirow (Ed.), Learning as transformation: Critical perspectives on a theory in progress (pp. 125-148). San Francisco: Jossey-Bass.

Capra, F., \& Luisi, P.L. (2014). The systems view of life. Cambridge: Cambridge University Press. 
Dieleman, H. (2015). Transdisciplinary hermeneutics: Working from the inner self, creating ecologies of knowing. Transdisciplinary Journal of Engineering \& Science (6), 72-85.

Durose, C., Richardson, L., \& Perry, B. (2018). Craft metrics to value co-production. Nature, 562, 4 October, 32-33.

Engels, A., \& Walz, K. (2018). Dealing with multi-perspectivity in real-world laboratories. Experiences from the Transdisciplinary Research Project Urban Transformation Laboratories. GAIA, 27 (S1), 39-45.

Hoffmann-Riem, H., Biber-Klemm, S., Grossenbacher-Mansuy, W., Hirsch Hadorn, G., Joye, D., Pohl, C., Wiesmann, U., \& Zemp, E. (2008). Idea of the handbook. In: Hoffmann-Riem, H., Biber-Klemm, S., Grossenbacher-Mansuy, W., Hirsch Hadorn, G., Joye, D., Pohl, C., Wiesmann, U., \& Zemp, E. (Eds.) Handbook of transdisciplinary research (pp. 3-17). Berlin: Springer.

Illeris, K. (2013). Transformative learning and identity. Abingdon, Oxon: Routledge.

Klein, J. T. (2015). Reprint of "Discourses of transdisciplinarity: Looking back to the future", Futures, 65, 10-16.

Longhurst, N. (2015). Towards an "alternative" geography of innovation: Alternative milieu, socio-cognitive protection and sustainability experimentation. Environmental Innovation and Societal Transitions, 17, $183-$ 198. http://dx.doi.org/10.1016/j.eist.2014.12.001

Loorbach, D., Frantzeskaki, N., \& Avelino, F. (2017). Sustainability transitions research: Transforming science and practice for societal change. Annual Review of Environment and Resources, 42, 599-626. https://doi. org/10.1146/annurev-environ-102014-021340

Mezirow, J. (1991). Transformative dimensions in adult learning. San Francisco: Jossey-Bass.

Murphy, J.T. (2015). Human geography and socio-technical transition studies: Promising intersections. Environmental Innovation and Societal Transitions, 17, 73-91. http://dx.doi.org/10.1016/j.eist.2015.03.002

Nicolescu, B. (2002). Manifesto of transdisciplinarity. Albany, NY: SUNY Press.

Nikulina, V., Larson Lindal, J., Baumann, H., Simon, D., \& Ny, H. (2019). Lost in translation: A framework for analysing complexity of co-production settings in relation to epistemic communities, linguistic diversities and culture. Futures, 113, 102442, https://doi.org/10.1016/j.futures.2019.102442.

Patel, Z., Greyling, S., Simon, D., Arfvidsson, H., Moodley, N., Primo, N., \& Wright, C. (2017). Local responses to global sustainability agendas: Learning from experimenting with the urban sustainable development goal in Cape Town. Sustainability Science. doi: 10.1007/s11625-017-0500-y.

Perry, B., Patel, Z., Bretzer, Y.N., \& Polk, M. (2018). Organising for co-production: Local interaction platforms for urban sustainability. Politics and Governance, 6(1), 189-198.

Puerari, E., de Koning, J.I.J.C., von Wirth, T., Karré, P. M., Mulder, I.J., \& Loorbach, D.A. (2018). Co-creation dynamics in urban living labs. Sustainability, 10(1893). doi: 10.3390/su10061893

Ramadier, T. (2004). Transdisciplinarity and its challenges: The case of urban studies. Futures 36, 423-439. doi: 10.1016/j.futures.2003.10.009.

Reason, P., \& Bradbury, H. (2001). Introduction: Inquiry and participation in search of a world worthy of human participation. In: Reason, P., \& Bradbury, H. (Eds.). Handbook of action research (pp. 1-14). London: Sage.

Riedy, C. (2007). The eye of the storm: An integral perspective on sustainable development and climate change response. Saarbrücken: VDM.

Schäpke, N., Stelzer, F., Caniglia, G., Bergmann, M., Wanner, M., Singer-Brodowski, M., Loorbach, D., Olsson, P., Baedeker, C., \& Lang, D.J. (2018). Jointly experimenting for transformation? Shaping real-world laboratories by comparing them. GAIA, 27(S1), 85-96.

Sen, A. (2000). Development as freedom. Oxford: Oxford University Press.

Simon, D. (Ed.) (2016). Rethinking sustainable cities: Accessible, green and fair. Bristol: Policy Press.

Sommerville, M.A. \& Rapport, D.J. (Eds.) (2000). Transdisciplinarity: Recreating integrated knowledge. Oxford: EOLSS Publishers.

Taylor, E.W. (2007). An update of transformative learning theory: A critical review of the empirical research (1999-2005). International Journal of Lifelong Education, 26(2), 173-191.

WBGU (German Advisory Council on Global Change) (2011). World in transition: A social contract for sustainability. Flagship report. Retrieved from http://www.wbgu.de/fileadmin/templates/dateien/veroeffentlichungen/hauptgutachten/jg2011/wbgu_jg2011_en.pdf

Woiwode, C. (2013). New departures in tackling urban climate change: Transdisciplinarity for social transformation (a critical appraisal of the WBGU's 2011 Report). Integral Review, 9(2), 384-412. www.integralreview.org. 